\title{
Implementing a structured triage system at a community health centre using Kaizen
}

\section{AA Isaacs MBChB, MFamMed \& DA Hellenberg MBChB, MFamMed, FCFP(SA)}

To cite this article: AA Isaacs MBChB, MFamMed \& DA Hellenberg MBChB, MFamMed, FCFP(SA) (2009) Implementing a structured triage system at a community health centre using Kaizen, South African Family Practice, 51:6, 496-501, DOI: 10.1080/20786204.2009.10873913

To link to this article: http://dx.doi.org/10.1080/20786204.2009.10873913
а (c) 2009 SAAFP. Published by Medpharm.

曲 Published online: 15 Aug 2014.

Submit your article to this journal $\pi$

山 Article views: 97

Q

View related articles ¿ 


\title{
Implementing a structured triage system at a community health centre using Kaizen
}

\author{
${ }^{\mathrm{a}}$ Isaacs AA, MBChB, MFamMed ${ }^{\mathrm{b}}$ Hellenberg DA, MBChB, MFamMed, FCFP(SA) \\ ${ }^{a}$ Metro District Health Services (Western Cape) and Division of Family Medicine, Faculty of Health Sciences, University of Cape Town \\ ${ }^{b}$ Division of Family Medicine, Faculty of Health Sciences, University of Cape Town \\ Correspondence to: Dr AA Isaacs, e-mail: aaisaacs@pgwc.gov.za \\ Keywords: triage; casualty; Kaizen; Lean; management
}

\section{Abstract}

SA Fam Pract 2009;51(6):496-501

Background: More than 100 unbooked patients present daily to the Mitchell's Plain Community Health Centre (MPCHC), and are triaged by a doctor, with the assistance of a staff nurse. The quality of the triage assessments has been found to be variable, with patients often being deferred without their vital signs being recorded. This leads to frustration, and a resultant increased workload for doctors; management is concerned with the medicolegal risk of deferring patients who have not been triaged in accordance with the guidelines; and patients are unhappy with the quality of service they receive.

Aim: We set out to standardise the triage process and to manage unbooked patients presenting to the community health centre (CHC) in a manner that is medico-legally safe, cost efficient and patient friendly, using the Kaizen method.

Methods: The principles of Kaizen were used to observe and identify inefficiencies in the existing triage process at the MPCHC. Findings were analysed and interventions introduced to improve outcomes. The new processes were, in turn, validated and standardised.

Results: The majority of patients presenting to Triage were those needing reissuing of prescriptions for their chronic medication, and this prevented practitioners from timeously attending to other patients waiting to be seen. Reorganising of the process was needed; it was necessary to separate the patients needing triage from those requiring only prescriptions to be reissued. After the intervention, triage was performed by a staff nurse only, using the Cape Triage Score (CTS) method. Subsequent to the implementation of interventions, no patients have been deferred, and all patients are now assessed according to a standardised protocol. The reasons for patients requiring reissuing of prescriptions were numerous, and implementing countermeasures to the main causes thereof decreased the number of reissues by $50 \%$.

Conclusion: The Kaizen method can be used to improve the triage process for unbooked patients at the MPCHC, thereby improving the quality of services delivered to these patients. As the needs of the various CHCs differ quite widely across the service platform, the model needs to be adapted to suit local conditions.

(P) Peer reviewed. (Submitted:2008-11-13, Accepted:2009-02-06). ๑ SAAFP

\section{Introduction}

The Mitchell's Plain Community Health Centre (MPCHC) is one of the busier community health centres (CHCs) in the Cape Metropolitan (Metro) Region: it has about 900 patient visits daily. ${ }^{1}$ Staff members can comfortably attend to $750-800$ patients per day, but it is common to have more patients arriving at the hospital than can reasonably be expected to be seen by the available clinicians. In the current system a doctor, with the assistance of a nurse, is allocated to manage the excess patients in Triage.

Triage soon became a "dumping ground", to where any patient was sent, as it offered a convenient way out of having to enter into discussion with patients around their expectations. Patients could also present directly to Casualty where they were "Cape Triaged"2 and then seen in Casualty if it was a genuine emergency or referred back to Triage. This resulted in a parallel triage system with the patients deciding which one they would access.
The previous system constituted a medico-legal risk as patients were often deferred to the next day without being seen by a health professional, and some ill patients sometimes had to wait for several hours before being attended to. The situation deteriorated to such an extent that doctors dreaded working in Triage, as the workload often increased to more than 100 patients daily. ${ }^{1}$ The Facility Manager received numerous complaints from patients having to wait for long periods before being seen in Triage. There were also numerous requests for more than one doctor to work in Triage, but there was no spare capacity to meet this request.

\section{Problem statement}

There were too many patients for the triage doctor to deal with, resulting in patients being inadequately assessed and having to return on another day. Some of the consequences of this system were:

- III patients not being assessed early enough

- Patients deferred without being assessed 
- Sub-optimal patient flow, as evidenced by long queues

- Angry and frustrated patients

- Low staff morale.

\section{Ethical considerations}

The situation described above was also being experienced at other $\mathrm{CHCs}$ in the Cape Metro Region (one of four Health Districts in the Western Cape). The Western Cape Department of Health appointed a task team to assess the triage system at a cross-section of CHCs and make recommendations to the Metro Clinical Management Forum (a twomonthly meeting of all the senior doctors at CHCs in the Cape Metro). The task team recommended that all unbooked patients should be assessed using the CTS. However, there was an understanding that a uniform triage system could not be applied to all CHCs, as local conditions varied greatly between facilities. CHCs were thus requested to improve their triage systems taking their specific conditions into account.

No formal ethical approval was applied for as this audit took place in the context of a provincial health department managerial process. The authors obtained permission from the Directorate for District Health Services and Special Programmes in the Western Cape Health Department to publish the audit findings.

\section{Aim}

The overall aim was to develop a system to manage unbooked patients presenting to the MPCHC in a medico-legally safe, cost efficient and patient friendly manner, using the Kaizen method.

\section{Objectives}

- To evaluate the triage process in order to identify existing inefficiencies

- To analyse the findings and introduce interventions to optimise patient flow, and

- To subsequently standardise the triage process.

\section{Methods}

The principles of Lean and Kaizen were used to analyse and improve the triage process.

\section{Background to Lean and Kaizen}

The roots of Lean can be traced back to the early 1900s, with Henry Ford and the mass production of cars. ${ }^{3}$ Lean thinking was further developed in the 1960s by Taiichi Ohno, as the Toyota Production System. ${ }^{4}$ In this management philosophy emphasis is placed on training, standardisation and human creativity. ${ }^{3}$ The quest for continuous improvement was initially small, but eventually became very successful in the Toyota company. It has subsequently been applied with great benefit in many service industries, including health care. ${ }^{3}$ The benefits of Lean include removing wasteful activities from and decreasing time for processes, reducing defects and errors, improving productivity and increasing client satisfaction. $^{3}$

Kaizen was initiated in Japan following World War II. The word Kaizen means "continuous improvement". It comes from the Japanese words "Kai" meaning school and "Zen" meaning wisdom. ${ }^{5}$ Kaizen is the heart of Lean Manufacturing (also known as the Toyota Production System). Toyota states that: “...based on the concept of continuous improvement, or Kaizen, every Toyota team member is empowered with the ability to improve their work environment." 6

Kaizen can be viewed as a tool within the Lean system. It involves a series of activities through which change can be implemented in an organisation. It is a carefully planned, structured event to improve a specific area of an organisation in a quick and focused manner. ${ }^{3}$ Kaizen involves setting standards and then continually improving those standards. It aims to eliminate hard work, both mental and physical, while simultaneously teaching employees how to evaluate their work processes using the scientific method. ${ }^{\text {? }}$

There is much overlap between Lean and the Quality Improvement Cycle (QIC). Figure 1 shows the development of Lean and the development of Statistical Quality Control (SQC) into Total Quality Control (TQC), and eventually into Six Sigma. ${ }^{3}$

Figure 1: Development of Lean Six Sigma ${ }^{3}$

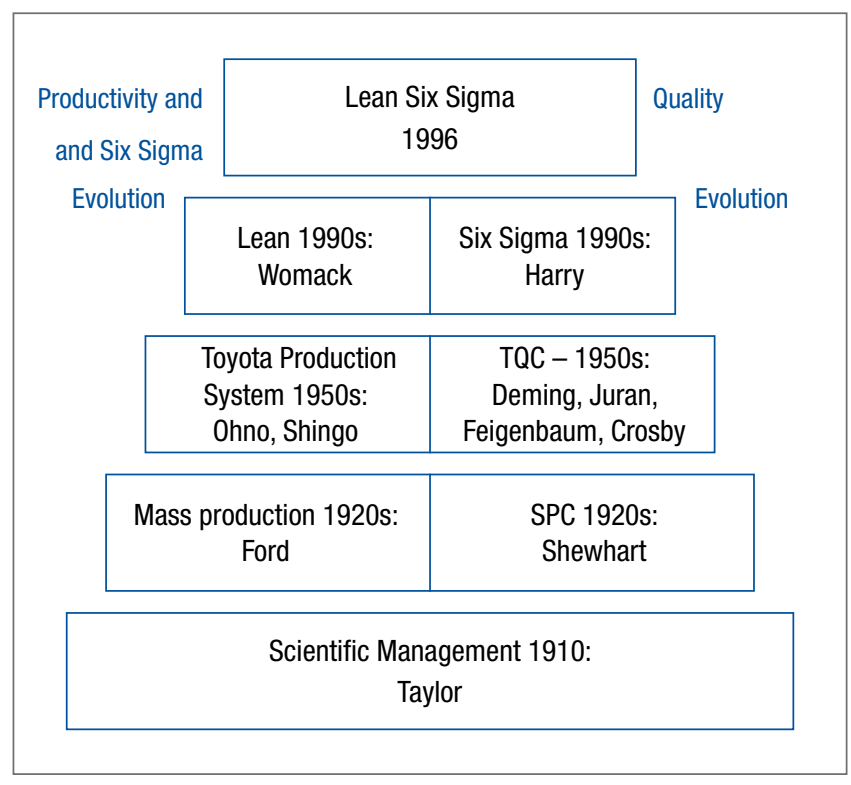

Lean is thought of as focusing more on productivity and Six Sigma more on quality. Currently, many companies employ practitioners who use Lean Six Sigma, which combines all the best approaches to increasing productivity and improving quality into one system. The basic steps followed in a Kaizen project are shown in Figure $2 .^{5}$

Figure 2: Steps in a Kaizen project. ${ }^{5}$

\begin{tabular}{|c|}
\hline \multicolumn{1}{|c|}{ Step 10: To standardise new systems } \\
\hline Step 9: To review results \\
\hline Step 8: To try-out countermeasures \\
Step 6: To develop countermeasures \\
\hline Step 5: To identify wastes and problems \\
\hline Step 4: To measure efficiency and wastes \\
\hline Step 3: To measure output and productivity \\
\hline Step 2: To visualise/illustrate operations \\
\hline Step 1: To understand workplace and its operations \\
\hline
\end{tabular}




\section{Understanding the workplace and its operations}

First, we had to determine the reasons for patients presenting to Triage. A brainstorming session was held with doctors who had previously worked in Triage, and this group identified five categories of patients, viz:

- Unbooked patients who needed to see a doctor (i.e. true triage patients)

- Those who needed prescriptions re-issued

- Those who needed dressings and needed a certificate for work

- Those who needed acute medication that could be dispensed at Triage

- Those who came for the results of laboratory investigations

We categorised all patients who presented to Triage during the week 4-8 Feb 2008. The results are graphically illustrated in Figure 3.

Figure 3: Categories of patients presenting to Triage at MPCHC during the week 4-8 Feb 2008

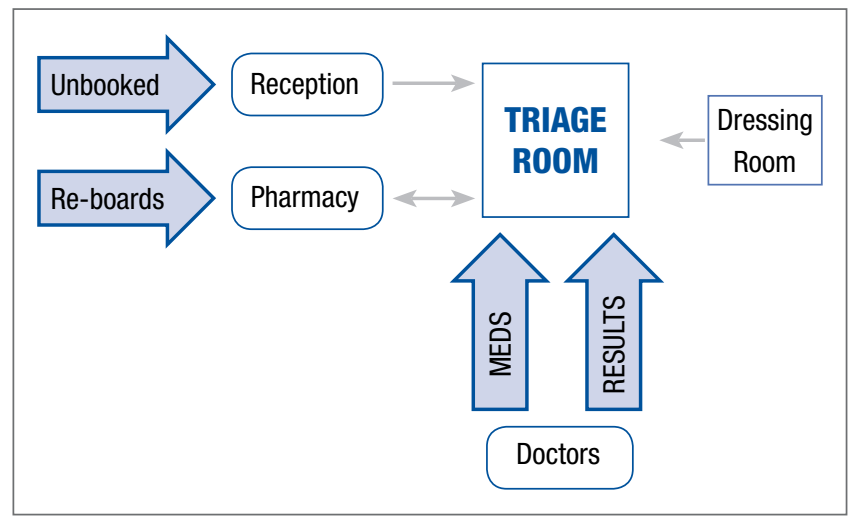

The next step was to quantify the number/percentage of patients in the various identified categories who attended Traige. Results are shown in Figure 4.

Figure 4: Percentage of patients in the identified categories attending Triage

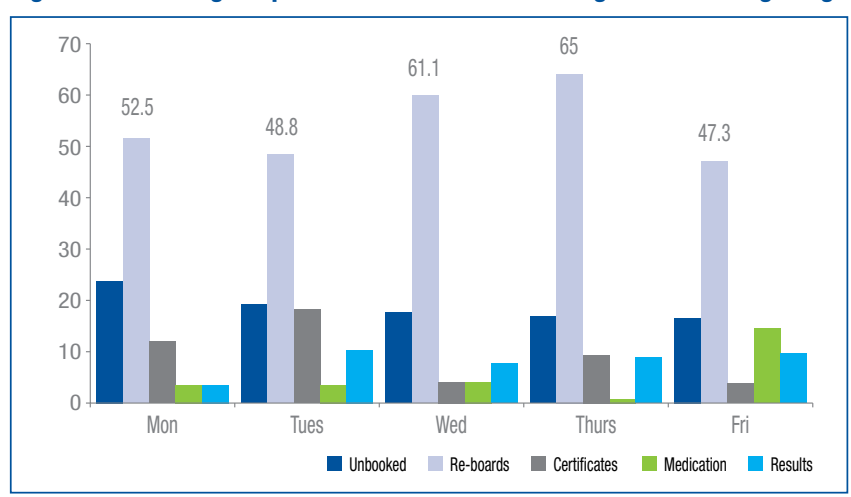

It was clear that the number of patients requiring re-issuing of prescriptions was the main contributor to triage numbers: it accounted for more than half of the patients on most days of the week. The actual number of patients requiring Triage was only $10-20 \%$ of the workload. The other three categories were less significant: each accounted for $10 \%$ or less.

\section{Findings and analysis of problem}

The Pareto principle, or $80 / 20$ rule, states that a certain $20 \%$ of your input contributes to $80 \%$ of your output. ${ }^{5}$ It is clear that the number of patients requiring re-issuing of prescriptions contributes most to the triage numbers. Identifying (and addressing) the reasons why patients presented to Triage for repeat prescriptions would thus contribute to significantly decreasing triage numbers.

Fishbone analysis ${ }^{5}$ was then used to brainstorm possible reasons for the above problem, and these were then validated or eliminated as contributing to the cause of the problem (see Figure 5). There were numerous reasons for patients needing to have their prescriptions reissued. Four broad categories were identified:

- Patients had defaulted and their scripts were no longer valid.

- CHC staff errors (i.e. doctors' prescription errors, lost folders, appointment errors between pharmacy and reception)

- Chronic Dispensing Unit (CDU) problems

- No original script from referring hospital, therefore the MPCHC pharmacist could not dispense off the copy of the script.

Figure 5: Findings and fishbone analysis

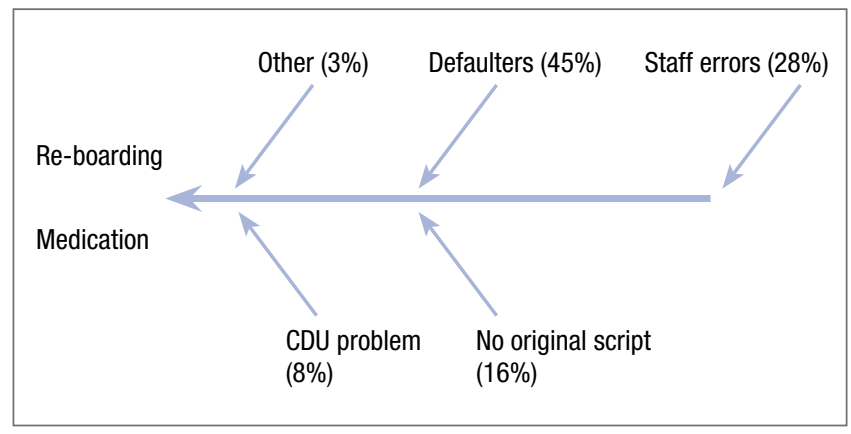

The causes were determined by surveying 100 patient folders of patients who presented for re-issuing of prescriptions, and the following was found:

Defaulters $-45 \%$

CHC staff errors $-28 \%$

No original script $-16 \%$

CDU errors $-8 \%$

Other $-3 \%$

\section{Root cause analysis}

In order to identify the root causes of the problem and to develop countermeasures, we proceeded with the " 5 whys". The " 5 Whys" is a tool used to determine the root cause of a problem by asking "why" until the root cause is identified. "Why" does not have to be asked exactly 5 times, only until the root cause is identified. This is illustrated for the defaulters in Table I below:

The " 5 whys" applicable to the other categories can be found in Table II below. Once the root cause(s) of the problem had been identified, the countermeasures became more focused and practical.

In order to establish a structured system, all the categories of patients identified had to be accommodated. A protocol was developed whereby all unbooked patients would be triaged by a nurse, using the CTS, thus freeing the doctor to consult with patients. For the re-issuing of prescriptions, those due to staff errors were differentiated from those due to poor patient compliance, and those as a result of staff errors were attended to by clinicians in the Prep room (nursing area where preparatory tests were carried out, e.g. blood sugars, urine, $\mathrm{Hb}$ and weights, prior to 
Table I: Root cause analysis and countermeasures for why patients default, exploring two roots.

\begin{tabular}{|c|c|c|c|c|c|}
\hline \multicolumn{6}{|c|}{ The 5 Whys } \\
\hline Problem & Why? & Why? & Why? & Why? & Countermeasure \\
\hline Patients default (root 1) & $\begin{array}{l}\text { They do not understand } \\
\text { the importance of being } \\
\text { compliant }\end{array}$ & $\begin{array}{l}\text { It has never been } \\
\text { explained to them }\end{array}$ & $\begin{array}{l}\text { It is not seen as a priority } \\
\text { by staff }\end{array}$ & $\begin{array}{l}\text { Nobody is responsible for } \\
\text { educating the patents }\end{array}$ & $\begin{array}{l}\text { Compliance counselling } \\
\text { be offered by a Health } \\
\text { Promotion Officer }\end{array}$ \\
\hline Patients default (root 2) & $\begin{array}{l}\text { They do not see it as a } \\
\text { priority to collect their } \\
\text { medication/s on time }\end{array}$ & $\begin{array}{l}\text { A doctor will re-board it } \\
\text { anyway }\end{array}$ & & & $\begin{array}{l}\text { Medication be re-boarded } \\
\text { the next day by a team of } \\
\text { doctors after compliance } \\
\text { counselling }\end{array}$ \\
\hline
\end{tabular}

Table II: Root cause analysis and countermeasures for the remaining problems identified.

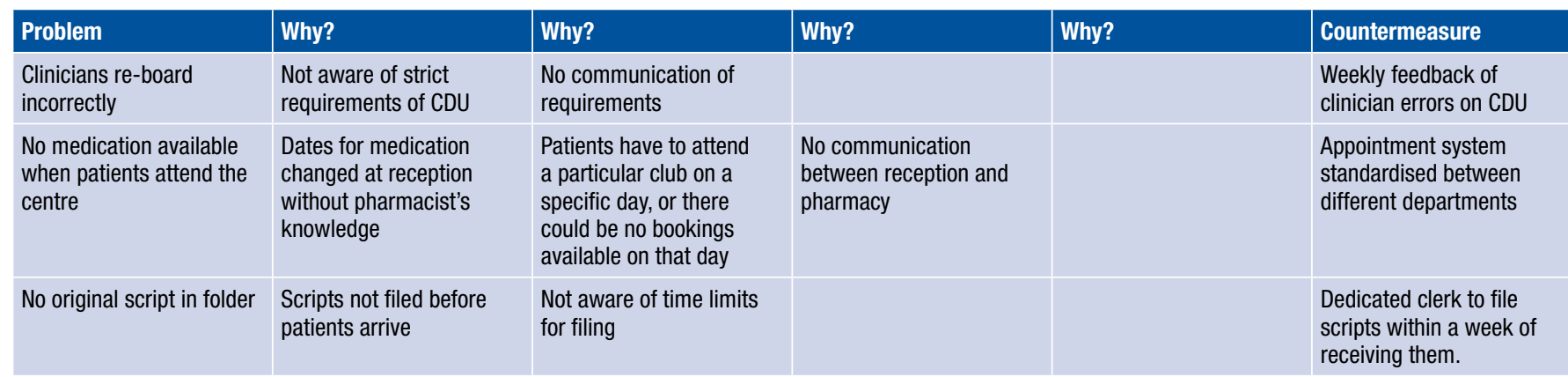

the patient seeing the doctor) every 30-45 minutes, when coming to collect their patient folders. This levelling of the workload is a key Lean principle to prevent the development of bottlenecks. Patients who were non-compliant had to return the next day and receive their medication after agreeing to compliance counselling from a Health Promotion Officer (HPO). Certificates were completed by the triage nurse and signed by the doctors in the Prep room. Patients attending for laboratory results were added to the clinician-patient total for the day.

The dispensing of acute medication from the triage room was discontinued, as the numbers were too few to justify the extra work needed to monitor and control the medication at this site. In this way, all those categories of patients that previously crowded Triage were managed without interfering with the actual triage patients. Patient flow after implementation of Kaizen is shown schematically in Figure 6.

\section{Structured triage system}

The Principal Medical Officer (PM0) or senior doctor calculates how many patients can be seen each day, based on the available staff, e.g. 5 clinicians $\times 45$ patients $=225$. The number of appointments (example 90) is subtracted from this amount. This new total (135) will be the number of unbooked patients that can be admitted. The PMO then communicates with Reception to admit about 120 unbooked patients, i.e. leaving room for " 15 " $(135-120=15)$ patients who could be referred from Triage.

The first 120 unbooked patients will be admitted and sent to the Prep room for clinicians to see. Any unbooked patients following the initial 120 will be triaged by an Enrolled Nurse Assistant (ENA) using the CTS. "Yellow" patients are sent to the Prep room, "orange" or "red" to the Emergency Room (ER). All patients identified by the ENA who are not

Figure 6: Patient flow after implementation of Kaizen
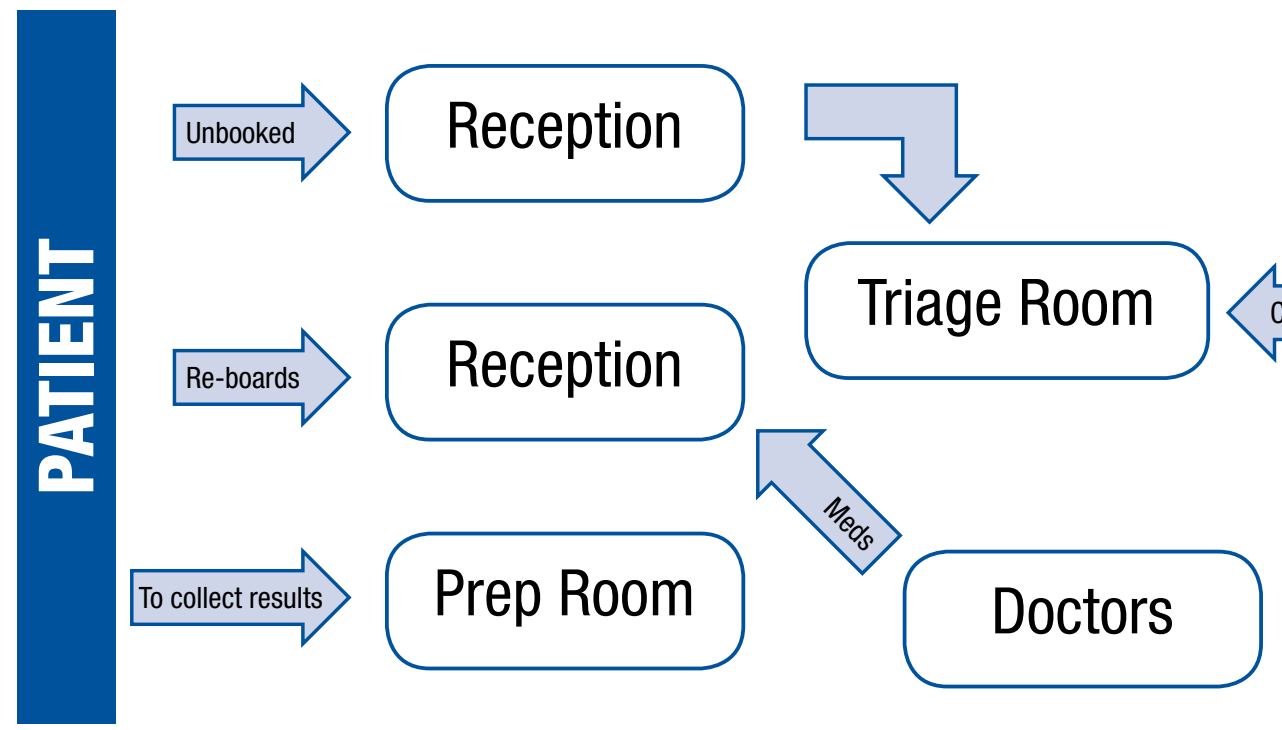
Certificates 
"green" will be admitted. This number should preferably be less than the "15", but if more, should still be admitted. It is important for the PMO to communicate to the "green" patients that they will most likely not be seen and that they should rather make an appointment to return on another day. The appointments must then be honoured. Figure 7 is a schematic representation of patient flow at $8 \mathrm{am}$ (in a structured triage system).

Figure 7: Patient flow at 8am

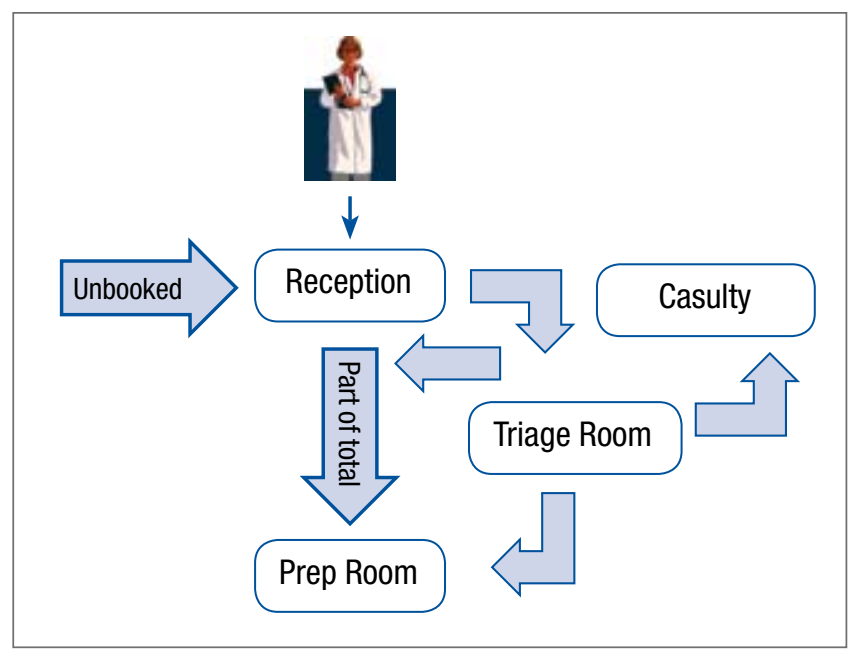

At 12 noon the PM0 checks with Reception to ascertain whether all booked patients have arrived. For every appointment that did not arrive, another "green" can be admitted. If there are less than " 15 " yellow cases triaged by 12 noon, additional green cases can be admitted to make up the "15". Figure 8 is a schematic representation of patient flow at noon (in a structured triage system).

Figure 8: Modified patient flow at noon.

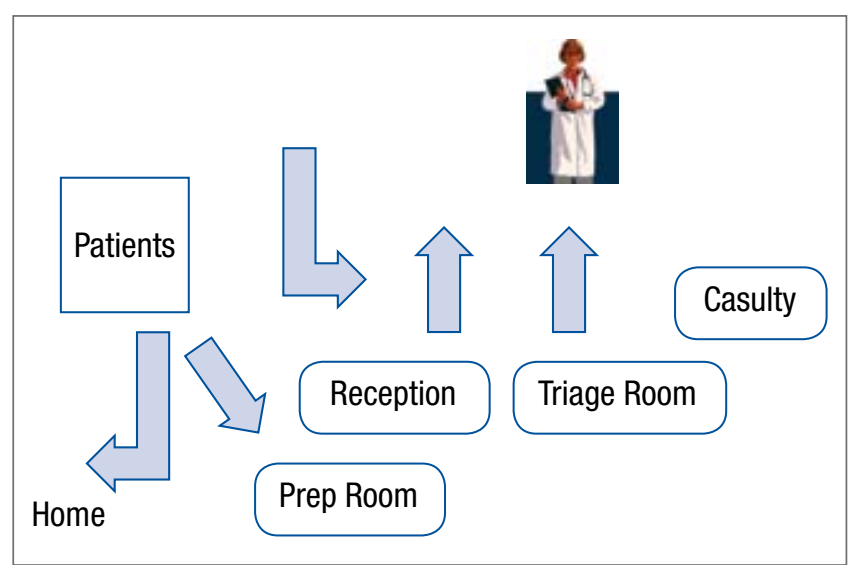

\section{Findings after the implementation of countermeasures}

After implementing the countermeasures to the large number of patients requiring re-issuing of prescriptions, the daily average was decreased from 46 to 37 after one month. Three months after implementation of the countermeasures it had decreased to 22 re-issues per day (see Figure 9).

\section{Sustaining our plans}

In order to sustain our efforts it was important to obtain a commitment from management, especially the Nursing Manager, to ensure that there
Figure 9: Findings after countermeasures: number of re-issues per day

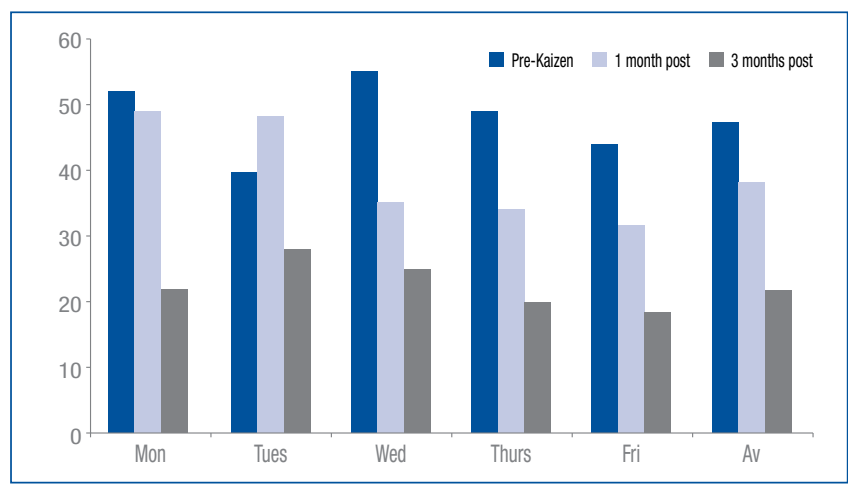

would always be a nurse available for Triage. Once new standardised practices had been agreed upon, a week-long training period was arranged for all staff involved to enable them to familiarise themselves with the system. Responsibility for monitoring different aspects of the system was allocated to individuals from different departments and was made part of their Individual Performance Plan. Initially, weekly feedback sessions were held to iron out teething problems, but thereafter, feedback sessions became a monthly discussion item on the agenda at the Heads of Department meeting.

A Standard Operating Procedure (SOP) was developed for the process involving the Triage patients (see Appendix 1).

\section{Limitations of using the Kaizen system}

It is essential to allow sufficient time before commencing with a new project, for staff to familiarise themselves with the Kaizen method. If there is no staff buy-in to participate in a project then it is unlikely that the desired outcomes will be achieved. Kaizen typically focuses on one aspect of a system and changes in one area may have an unexpected knock-on effect in another area.

\section{Future plans}

As Kaizen is about continuous improvement, there will be a continuous endeavour to improve on previous performance by responding to feedback and suggestions from patients and staff. The performance of nurses in implementing the CTS needs to be monitored and audited. A further intervention from the $\mathrm{CDU}$ is the initiation of home deliveries of medication and this has, initially, been offered to the defaulters. The next area in patient flow that needs attention is the Prep room process. Kaizen has also been successfully used to improve waiting times at our reception and pharmacy areas. Similar projects could also be initiated in other areas in our facility, such as the rehabilitation service or antiretroviral (ARV) clinic. In the longer term the monitoring of excess patients would guide the restructuring of our staff establishment.

\section{Conclusion}

By using Kaizen, our triage area was transformed from one of relative chaos to one with a structured process. Kaizen used the expertise of the workers involved in the process, who then developed solutions to the problems using objective data. Implementation was thus facilitated and the staff took ownership of the new process.

Our triage system may not be applicable to other CHCs in the Cape Metro but, by using Kaizen, these CHCs could identify their own specific challenges and solve them using local expertise. 


\section{Acknowledgements}

We would like to acknowledge Drs Antonio Booysen and Giovanni Perez for assisting us in applying the Lean methodology. We thank the staff of the Mitchell's Plain Community Health Centre (especially the Facility Manager Ms L Apollis, as well as the Triage, Prep Room and Reception staff) for their patience in implementing the new system. We also wish to thank Ms Z Davis and Ms B Bredekamp of the UCT Division of Family Medicine for their assistance in typing up and editing the manuscript. We declare that we have no financial or personal relationship(s) that may have inappropriately influenced us in writing this paper.

\section{References}

1. Mitchell's Plain Community Health Centre - Routine Monthly Report (RMR) statistics, 2007-2008.

2. Gottschalk SB, Wood D, DeVries S, Wallis LA, Bruijns $S$. The Cape triage score: A new triage system South Africa. Proposal from the Cape triage group. Emergency Medicine Journal 2006;23:149-53.

3. DeCarlo N; Breakthrough Management Group. The complete idiot's guide to Lean Six Sigma. New York: Alpha Press; 2007.

4. Alukal G, Sattler M, Manos A. Make healthcare lean. Quality Progress 2006;39(7):24-30.

5. Furuhashi Takeyuki. Workplace best practice - Practice of Kaizen in service organisations. Workshop at GF Jooste Hospital 2007

6. Kotelnikov V. Kaizen and total quality management (TQM) [monograph on the internet]. Business e-Coach; 2008 [cited 2008 Mar 5]. Available from http://www.1000ventures.com/business guide/ mgmt kaizen tac main.html

7. Wikipedia. Kaizen. [monograph on the internet]. Wikipedia, the free encyclopedia; 2008 [cited 2008 Mar 8]. Available from http://en.wikipedia.org/wiki/Kaizen

\section{Appendix 1: Standard Operating Procedure for Triag e}

PMO:

- 8 am, calculate how many patients can be seen

- Subtract appointments

- Allow for triaged "yellow" patients

- Communicate the total to Reception

- Communicate with patients:

- Explain the staff situation

- Inform them as to which numbers will be admitted and who will go to the triage room

- Recommend that "green" patients make an appointment

- Inform them that some "greens" might be seen after 12 pm

- 12 pm, check the totals from Triage, Reception (appointments that did not arrive)

- Admit more "green" patients

Reception:

- Issue stickers to unbooked patients as they arrive

- Admit unbooked patients based on figures received from PMO

- Keep track of appointments that do not arrive

- Inform PMO of number of defaulters at $12 \mathrm{pm}$

- Keep track of new appointments for the next day

ENA/Triage nurse:

- Triage all excess unbooked patients

- Send "oranges/reds" to casualty

- Keep track of "yellows" referred to the Prep room

- Ask "greens" to make an appointment or wait until 12 pm

- Inform PMO of "yellows" at 12 pm

\section{Monitoring:}

PMO:

- Audits the ENA/Triage performance on a monthly basis using a standardised audit tool

- Records daily number of re-boards (defaulters)

- Records daily number of non-appointments to be seen

Receptionist:

- Records daily the number of non-compliant appointments

- Records daily the number of stickers given to unbooked patients

ENA:

- Records the daily number of patients triaged, including those colour coded

- Records the daily number of re-boards (staff errors) 